\title{
ANALISIS KESENJANGAN DAN PEMODELAN PROSES BISNIS HUMAN CAPITAL MANAGEMENT PADA PTPN XI BERDASARKAN BEST PRACTICE SAP
}

\author{
Eko Wahyu Tyas Darmaningrat ${ }^{1}$, Hanim Maria Astuti ${ }^{2}$, Andhika Iman Rizqy \\ 1,2,3 Department of Information Systems, Faculty of Information and Communication Technology, Institut \\ Teknologi Sepuluh Nopember Surabaya, Indonesia \\ Email: ${ }^{1}$ tyas@is.its.ac.id, ${ }^{2}$ hanim@is.its.ac.id, ${ }^{3}$ andhika12@mhs.is.its.ac.id
}

(Naskah masuk: 17 Juli 2018, diterima untuk diterbitkan: 20 Desember 2018)

\begin{abstract}
Abstrak
Revolusi industri 4.0 dan persaingan bisnis yang semakin ketat menjadikan TI sebagai pendukung dalam pencapaian tujuan bisnis utama sebuah perusahaan. Salah satu bentuk dukungan TI dalam organisasi adalah penggunaan perangkat lunak Enterprise Resource Planning (ERP) dalam pengelolaan sumber daya perusahaan. Akan tetapi, dalam banyak kasus implementasi SAP tidak selalu membawa dampak sesuai dengan ekspektasi perusahaan. Hal ini disebabkan SAP menggunakan best practice yang belum tentu memiliki tingkat kesesuaian dengan proses bisnis perusahaan. Sehingga terdapat kesenjangan (gap) antara proses bisnis perusahaan yang digunakan sebagai acuan best practice oleh SAP dan perusahaan yang akan mengimplementasikan sistem ERP. Penelitian ini bertujuan untuk menyusun dokumen pemodelan proses bisnis as-is dan to-be serta mengidentifikasi kesenjangan antara proses bisnis yang sedang berjalan saat ini dengan proses bisnis pada best practice SAP khususnya pada modul Human Capital Management, salah satu modul utama SAP yang memainkan peran penting dalam membangun manajemen sumber daya yang baik di perusahaan. Hasil analisis kesenjangan memperlihatkan perubahan apa saja yang terjadi pada komponen proses bisnis, baik dari sisi aktivitas, sumber daya yang terlibat, kebutuhan kebijakan, dan struktur organisasi. Perubahan yang terjadi karena penerapan SAP sebagai sistem informasi SDM tentunya membawa dampak. Dampak yang diperoleh dari penerapan teknologi biasa disebut dengan nilai (value). Nilai tersebut berupa manfaat yang mengacu kepada peningkatan efisiensi proses kerja yang diterapkan dalam organisasi.
\end{abstract}

Kata kunci: Analisis Kesenjangan, Pemodelan Proses Bisnis, Enterprise Resource Planning (ERP), SAP, Human Capital Management

\section{GAP ANALYSIS AND BUSINESS PROCESS MODELING OF HUMAN CAPITAL MANAGEMENT BASED ON SAP BEST PRACTICE}

\begin{abstract}
Industrial revolution 4.0 and increasingly fierce business competition make IT as main supporter in achieving the main business objectives of an enterprise. One form of IT support within organizations is the use of Enterprise Resource Planning (ERP) software in enterprise resource management. However, the result of many SAP implementation cases do not always in line with the company expectations. This is because SAP used best practices that do not have the same level of compatibility with the company's business processes. Hence, there is a gap between the company's business processes used as the best practice reference by SAP and the company that will implement the ERP system. This study aims to establish as-is and to-be business process modeling documents and identify the gaps between current business processes of the organization and business processes in SAP best practices especially in the Human Capital Management module, one of SAP's main modules that plays an important role in building good resource management in the company. The gap analysis results show what changes occur in the business processes components in terms of activity, the resources involved, policy requirements, and organizational structure. These changes certainly would have some impacts. The impacts is usually called as value. This value is in the form of benefits that refer to an increase in the efficiency of work processes applied in the organization.
\end{abstract}

Keywords: Gap Analysis, Business Process Modeling, Enterprise Resource Planning (ERP), SAP, Human Capital Management 


\section{PENDAHULUAN}

Awalnya teknologi informasi (TI) hanya digunakan untuk kebutuhan militer di Amerika Serikat, namun kini hampir setiap masyarakat di seluruh dunia memiliki akses terhadap penggunaan TI untuk kepentingan mereka (Craiger, 1996). Penerapan TI sangat mendukung kinerja suatu organisasi, dimana inovasi TI sebagai faktor penting (Anasthasia, 2011). Keuntungan-keuntungan yang didapatkan dari perkembangan TI ini mendorong masyarakat untuk memanfaatkannya dalam kepentingan bisnis (business use), dimana hal ini membawa persaingan bisnis ke dalam level baru. Pada era industri 4.0 yang mengutamakan komputerisasi pabrik, penggunaan dukungan teknologi informasi dan komunikasi merupakan suatu keharusan agar perusahaan dapat meningkatkan efisiensi produksi, produktivitas, serta daya saingnya.

Enterprise Resource Planning (ERP) merupakan salah satu bentuk perkembangan teknologi informasi dalam pengelolaan sumber daya perusahaan yang dikembangkan dari aplikasi kalkulasi matematis sederhana yang saat itu dikenal dengan MRP (Management Resource Planning). ERP dapat meningkatkan kinerja, produktivitas, serta penurunan biaya operasional yang ada pada perusahaan atau organisasi yang mengimplementasikan SAP (Umble, 2003). SAP merupakan salah satu brand dari ERP yang banyak digunakan oleh perusahaan multinasional bersakala besar di berbagai belahan dunia. SAP dikenal karena merupakan salah satu ERP yang menyediakan best practice dari perusahaan-perusahaan ternama di dunia, sehingga memberikan panduan bagi perusahaan yang mengimplementasikannya bagaimana praktik terbaik yang seharusnya dijalankan agar performa perusahaan tersebut meningkat seiring dengan diimplementasikannya SAP ERP tersebut (SAP, 2016).

PT. Perkebunan Nusantara XI (Persero) merupakan perusahaan non listed dalam bidang usaha perkebunan tebu yang menghasilkan produk utama gula pasir dan tetes. Non listed adalah perusahaan-perusahaan publik yang sahamnya tidak diperdagangkan di lantai bursa, sehingga baik masyarakat, direksi, maupun dewan komisaris PTPN XI tidak mempunyai kepemilikan saham atas PTPN XI. Kepemilikan saham seluruhnya dimiliki oleh Pemerintah Republik Indonesia 100\% (PTPN XI, 2013). Sesuai dengan visinya, PTPN XI berusaha untuk mengikuti perkembangan jaman dan meningkatkan daya saing dengan mengimplementasikan SAP ERP untuk meningkatkan kinerja perusahaan dan menurunkan biaya operasional.

Setiap perusahaan yang akan mengimplementasikan sistem SAP diberi kesempatan untuk mengimplementasikan proses bisnis best practice yang dapat dijalankan melalui sistem ERP ini, sehingga perusahaan tersebut dapat mengikuti alur proses bisnis yang diambil dari best practice perusahaan-perusahaan ternama dunia melalui sistem ERP SAP (SAP, 2016). Mengingat setiap perusahaan atau organisasi memiliki karakteristik masing-masing yang dipengaruhi banyak faktor, maka perlu dilakukannya analisis kesenjangan (gap analysis) diantara alur proses bisnis keduanya, yaitu alur proses bisnis PTPN XI sendiri (as-is) dengan alur proses bisnis best practice (to-be) yang disediakan oleh sistem SAP.

Proses bisnis merupakan serangkaian kegiatan terstruktur yang dirancang untuk menghasilkan output tertentu (Davenport, 1993). Proses bisnis sendiri merupakan suatu kumpulan aktivitas atau pekerjaan terstruktur yang saling terkait untuk menyelesaikan suatu masalah tertentu atau yang menghasilkan produk atau layanan (demi meraih tujuan tertentu) (Widayanto, 2017). Proses bisnis merupakan salah satu faktor penting yang menentukan efektifitas dan pelayanan, terutama pada organisasi yang bergerak dengan TI sebagai support (Indrajit, 2001). Agar sistem SAP yang diimplementasikan dapat berjalan dengan efektif dan efisien di PTPN XI maka pada tahap persiapan implementasi SAP ERP sangatlah penting dan krusial untuk memahami proses bisnis yang sedang berjalan di PTPN XI (as-is) dengan memetakannya kedalam proses bisnis yang seharusnya (to-be) sesuai dengan best practice yang disediakan oleh SAP dan kondisi yang ada saat ini di PTPN XI.

SAP membagi fitur-fiturnya kedalam beberapa modul, salah satunya adalah modul Human Capital Management (HCM) yang akan diimplementasikan di PTPN XI. Modul HCM atau SAP ERP Human Capital Mangement (SAP ERP HCM) adalah sebuah solusi pengelolaan sumber daya manusia dalam sebuah perusahaan yang menyeluruh dan berkemampuan global. SAP ERP HCM memberikan perangkat pengelolaan informasi dalam mengola aset sumber daya manusia mereka (Cascio, 1990). Mengingat manusia merupakan sumber daya yang sangat penting dalam bidang industri dan organisasi. Implementasikan modul Human Resource atau HCM dapat menurunkan employee turnover serta meningkatkan revenue per worker (Parker, et al., 1988).

Pada penelitian ini akan dirumuskan pemodelan terhadap proses bisnis yang berjalan di lingkungan PTPN XI saat ini (as-is) dan proses bisnis yang diharapkan (to-be) khususnya pada modul HCM (Human Capital Management). sehingga diperoleh daftar kesenjangan (gap list) antara proses bisnis as-is dan to-be beserta dampaknya. SAP HCM adalah salah satu modul utama dalam SAP yang memainkan peran penting dalam membangun manajemen sumber daya yang baik di perusahaan. Selain itu, HCM adalah salah satu proses paling penting dalam organisasi lintas industri karena kompleksnya proses pengelolaan 
sumber daya manusia (SDM) pada organisasi atau perusahaan. Adapun tujuan dilakukannya analisis kesenjangan adalah untuk mengetahui apa saja perubahan-perubahan yang terjadi dari kondisi as-is ke kondisi to-be serta mengetahui dampak dari perubahan-perubahan yang terjadi. Analisa kesenjangan pada penelitian ini dilakukan berdasarkan quasi benefit analysis (Parker, et al., 1988), yang terbagi menjadi 4 kategori dampak, yakni value linking, value acceleration, value restructuring, dan innovation valuation.

\section{METODE PENELITIAN}

Pengerjaan penelitian ini tersusun atas beberapa langkah yang sistematis. Diagram alir pada Gambar 1 berikut menunjukkan uraian metodologi yang digunakan oleh penulis dalam penelitian ini.

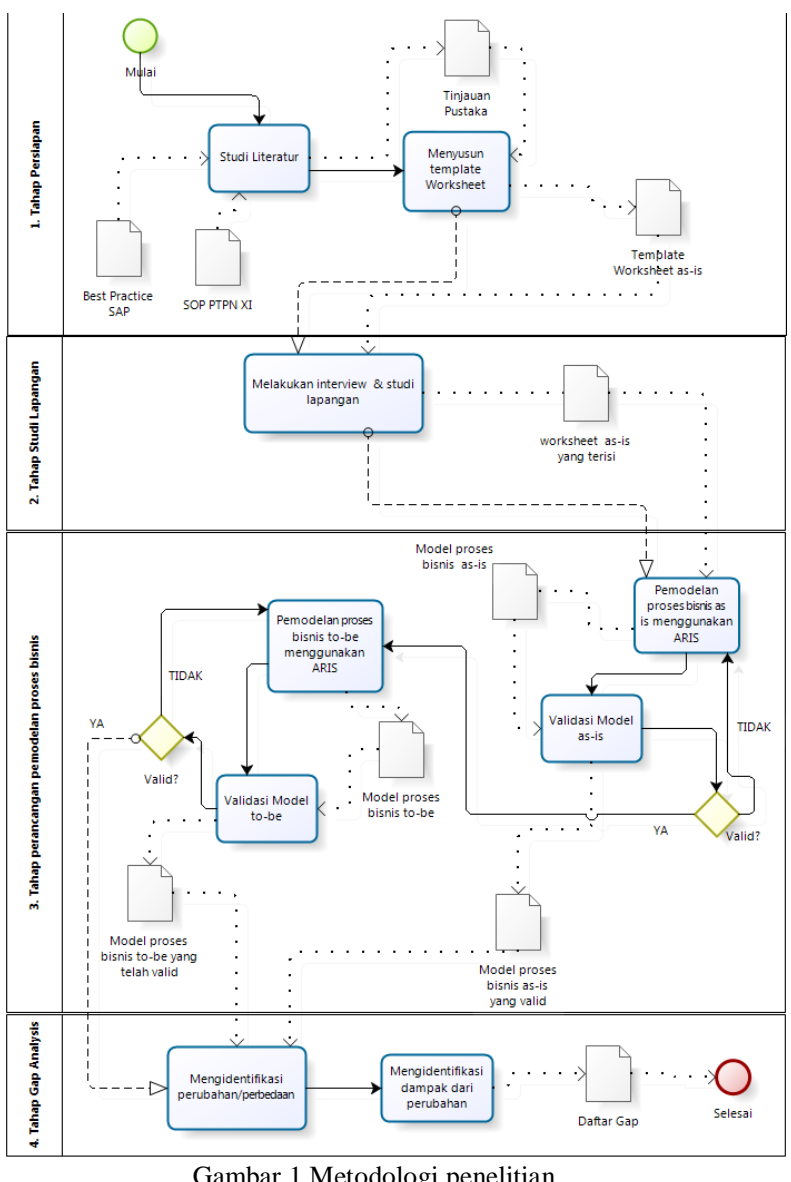

Pada tahap persiapan, selain mempelajari informasi mengenai proses bisnis divisi SDM PTPN XI dan modul HCM dari best practice yang dimiliki SAP, aktivitas utama dalam penelitian ini adalah penyusunan template worksheet proses bisnis as-is, yang akan digunakan pada tahap studi lapangan. Template ini disusun berdasarkan best practice modul HCM yang dimiliki oleh SAP.

Setelah didapatkan template worksheet dari tahap persiapan, dalam tahapan yang kedua, studi lapangan, penulis melakukan identifikasi proses bisnis yang sedang berjalan menggunakan template tersebut. Proses ini dilakukan melalui dua metode yakni observasi dan wawancara. Narasumber dalam penelitian ini adalah Kepala Urusan Personalia dan Hubungan Industrial, Kepala Urusan Pengembangan SDM, Staf Divisi SDM Bagian Penilaian Kinerja Karyawan, Staf Divisi SDM Bagian Pengembangan Sistem Informasi, Staf Divisi SDM Bagian Absensi, Staf Divisi SDM Bagian Penggajian, Staf Divisi SDM Bagian Pengelolaan data karyawan, serta Staf Divisi TI.

Tahapan ketiga adalah penyusunan model proses bisnis as-is dan to-be serta validasi model. Kemudian penulis melakukan indentifikasi dan analisa terhadap kesenjangan (gap) antara proses bisnis yang sedang berjalan (as-is) dengan proses bisnis yang disarankan oleh best practice SAP (tobe) yang didokumentasikan dalam bentuk gap-list

Tahapan yang terakhir adalah tahap analisis kesenjangan yang terdiri dari dua proses, yaitu proses identifikasi perubahan dan proses analisa dampak perubahan. Hasil analisis kesenjangan akan memperlihatkan perubahan apa saja yang terjadi pada komponen proses bisnis, baik dari sisi aktivitas, sumber daya yang terlibat, kebutuhan kebijakan, dan struktur organisasi. Perubahan yang terjadi karena penerapan SAP sebagai sistem informasi SDM tentunya membawa dampak. Dampak yang diperoleh dari penerapan teknologi biasa disebut dengan nilai (value). Nilai yang ada terkadang berupa manfaat yang mengacu kepada peningkatan efisiensi proses kerja yang diterapkan dalam organisasi.

\section{HASIL DAN PEMBAHASAN}

\subsection{Tahap Persiapan}

Untuk memudahkan proses wawancara pada penelitian ini, penulis membuat media berupa "Worksheet" yang berguna sebagai panduan serta merangkum hasil wawancara tersebut. Worksheet tersebut meliputi atribut-atribut pada setiap pertanyaan, atribut-atribut tersebut antara lain tujuan, indikator capaian, aktivitas, pemicu (trigger), standar/ kebijakan/ aturan yang berlaku, masukan proses, sumber, dokumen input, keluaran proses , dokumen luaran (output), langkah-langkah aktivitas, kendala aktivitas, dan harapan aktivitas. Worksheet tidak hanya diisi dari hasil wawancara melainkan juga pengkajian dokumen terkait seperti SOP serta observasi langsung di PTPN XI.

\subsection{Tahap Studi Lapangan}

Berdasarkan hasil wawancara dan observasi yang telah dilakukan, diketahui bahwa hampir seluruh proses bisnis Human Capital Management di PTPN XI terletak pada divisi SDM, namun proses bisnis Human Capital Management terhubung dengan seluruh divisi yang ada di PTPN XI. Proses 
bisnis divisi SDM di PTPN XI dibagi menjadi dua proses bisnis utama, yakni pengembangan sumber daya manusia dan pemeliharaan sumber daya manusia. Pengembangan sumber daya manusia merupakan serangkaian proses yang dijalankan oleh PTPN XI untuk memenuhi kebutuhan tenaga kerjanya, baik dari segi jumlah tenaga kerja maupun skill/ kapabilitas karyawannya. Sedangkan aktivitas pemeliharaan sumber daya manusia misalnya pengaturan penempatan, pemensiunan, pemberian kompensasi, jaminan sosial, dan lain sebagainya.

\subsection{Tahap Pemodelan Proses Bisnis}

Berdasarkan hasil dari worksheet tersebut dilakukan pemodelan proses bisnis as-is beserta proses bisnis to-be untuk memetakan alur kerja proses bisnis. Berdasarkan hasil pengumpulan data, didapatkan sebanyak 16 model proses Human Capital Management untuk kondisi eksisting (as-is) di PTPN XI dan 24 model proses Human Capital Management (to-be) berdasarkan best practice solusi SAP modul Human Capital Management (HCM). Model proses bisnis as-is yang telah dibuat dirangkum dalam Tabel 1. Nama proses umum kami sesuaikan dengan nama proses dalam SAP, sedangkan nama model bisnis merupakan istilah yang digunakan di PTPN XI.

Tabel 1 Nama model proses bisnis as-is

\begin{tabular}{lll}
\hline No & Proses Umum & Nama Model Proses Bisnis \\
\hline 1 & Organizational & Pembuatan Struktur Organisasi \\
2 & Management & Pembuatan Job Description \\
3 & Recruitment & Rekrutmen Internal \\
4 & & Penetapan Pejabat Puncak \\
5 & & Rekrutmen Eksternal \\
6 & Personnel & Pengelolaan Dossier Karyawan \\
7 & Administration & Mengupdate Aplikasi SDM \\
8 & & Memelihara Aplikasi Kepesertaan \\
& & Asuransi, Pensiun, \& Biaya \\
& & Perawatan Kesehatan \\
9 & Personnel & Pembuatan SKI \& RKT \\
10 & Development & Pelatihan \\
11 & & Pemberian BK \\
12 & & Pemberian PK \\
13 & Time Management & Perekapan Absensi \\
14 & Travel & Kalkulasi Biaya Perjalanan Dinas \\
& Management & (BPD) \\
15 & Termination & PHK Dengan Hormat \\
16 & & PHK Tidak Terhormat \\
\hline
\end{tabular}

Tabel 2 merupakan rangkuman dari daftar model proses bisnis to-be. Nama proses dalam table tersebut mengacu pada modul HCM dari SAP.

Tabel 2 Nama model proses bisnis to-be

\begin{tabular}{cll}
\hline No & Proses Umum & \multicolumn{1}{c}{ Nama Model Proses Bisnis } \\
\hline 1 & Organizational & Membuat Organizational Unit \\
2 & Management & Membuat Position \\
3 & & Membuat Jobs \\
\hline
\end{tabular}

\begin{tabular}{cll}
\hline No & Proses Umum & \multicolumn{1}{c}{ Nama Model Proses Bisnis } \\
\hline 4 & & $\begin{array}{l}\text { Mengelola Organizational } \\
\text { Management }\end{array}$ \\
5 & Recruitment & Hire/Rehire \\
6 & Personnel & Membuat HR Mini Master Record \\
7 & Administration & Mengelola Employee Master Data \\
8 & & Employee Transfer Administration \\
9 & & ESS \\
10 & & Leave of Absence \\
11 & & MSS - Time Sheet Approval \\
12 & & MSS - Leave Request Approval \\
13 & Personnel & Planning \\
14 & Development & Review \\
15 & & Training \& Event Management \\
16 & & Appraisal \\
17 & Time & Time Entry \\
18 & Managemnet & Workforce Time Processing \\
19 & & Time Admnistration \\
20 & & Time Processing - CATS \\
21 & & Time Evaluation Processing \\
22 & & FMLA Processing \\
23 & Travel & Travel Management \\
& Management & \\
24 & Termination & Employee Separation Administration \\
& & Processing \\
\hline & &
\end{tabular}

Pemodelan proses bisnis dilakukan menggunakan metode EPC (Event driven Process Chain) menggunakan ARIS (Scheer, et al., 2005). Adapun langkah-langkah yang dilakukan adalah sebagai berikut:

1. Menentukan start event atau kondisi yang merupakan event awal atau pemicu berjalannya proses.

2. Menentukan aktivitas-aktivitas yang dijalankan dari start event tersebut.

3. Menentukan atribut-atribut pada setiap aktivitas yang telah dimodelkan, seperti role, person, location, IT system, dan document.

4. Menentukan event setelah aktivitas dijalankan. Event setelah aktivitas mengindikasikan perubahan status/ kondisi pada proses.

5. Menentukan decision point atau percabangan seperti OR, XOR, maupun AND.

6. Menentukan end event untuk mengakhiri setiap proses yang ada. Berikut salah satu contoh hasil pemodelan proses bisnis as-is yakni model proses bisnis "Perekapan Absensi Karyawan" dapat dilihat pada Gambar 2.

Gambar 3 menunjukkan hasil pemodelan salah satu proses bisnis to-be yakni Time Entry melalui CATS (Cross Application Time Sheet), yang merupakan sistem absensi untuk merekam waktu kedatangan karyawan. 
Darmaningrat, dkk, Analisis Kesenjangan dan Pemodelan Proses Bisnis... 191

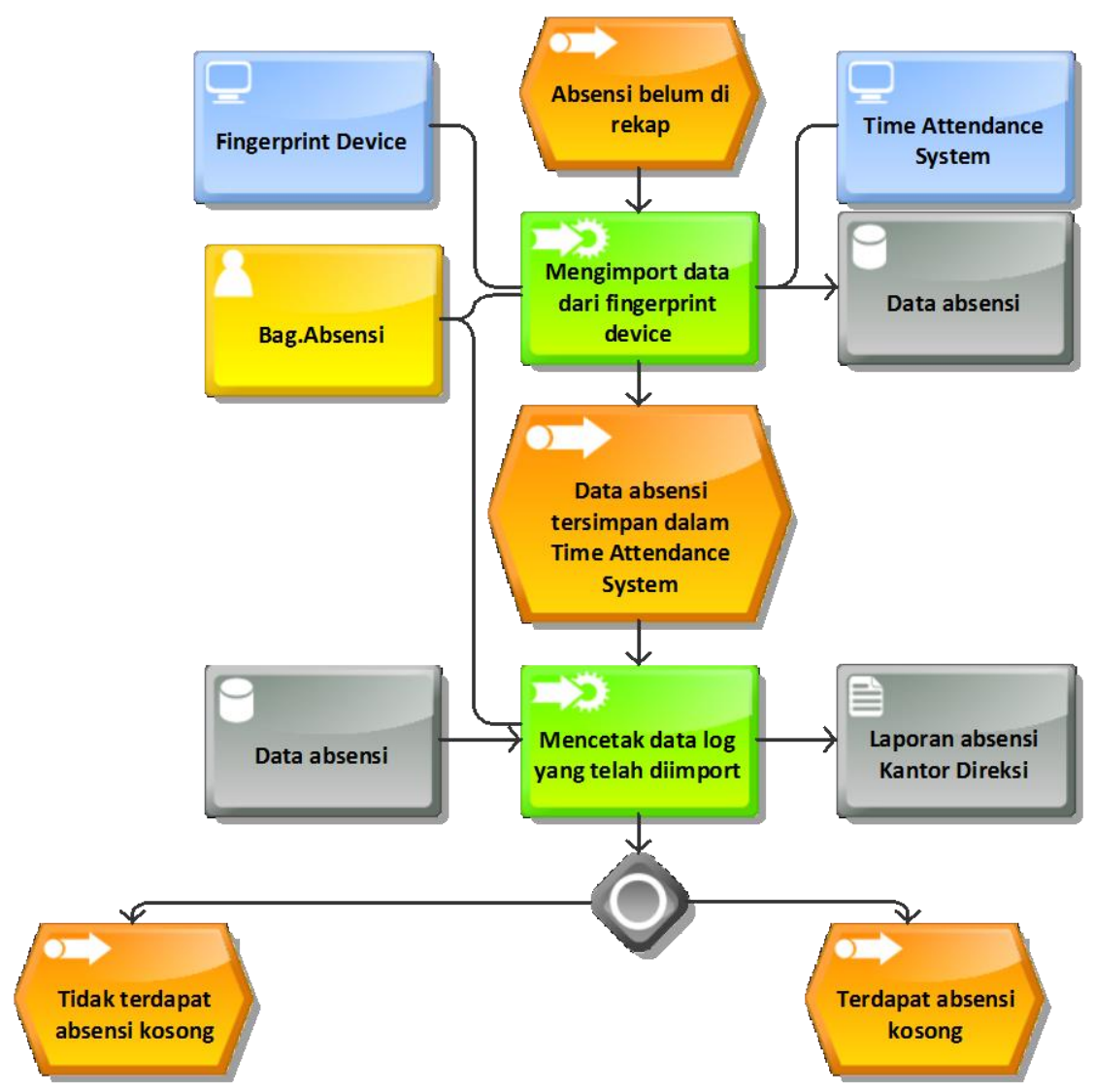

Gambar 2 Model proses perekapan absensi karyawan (as-is)

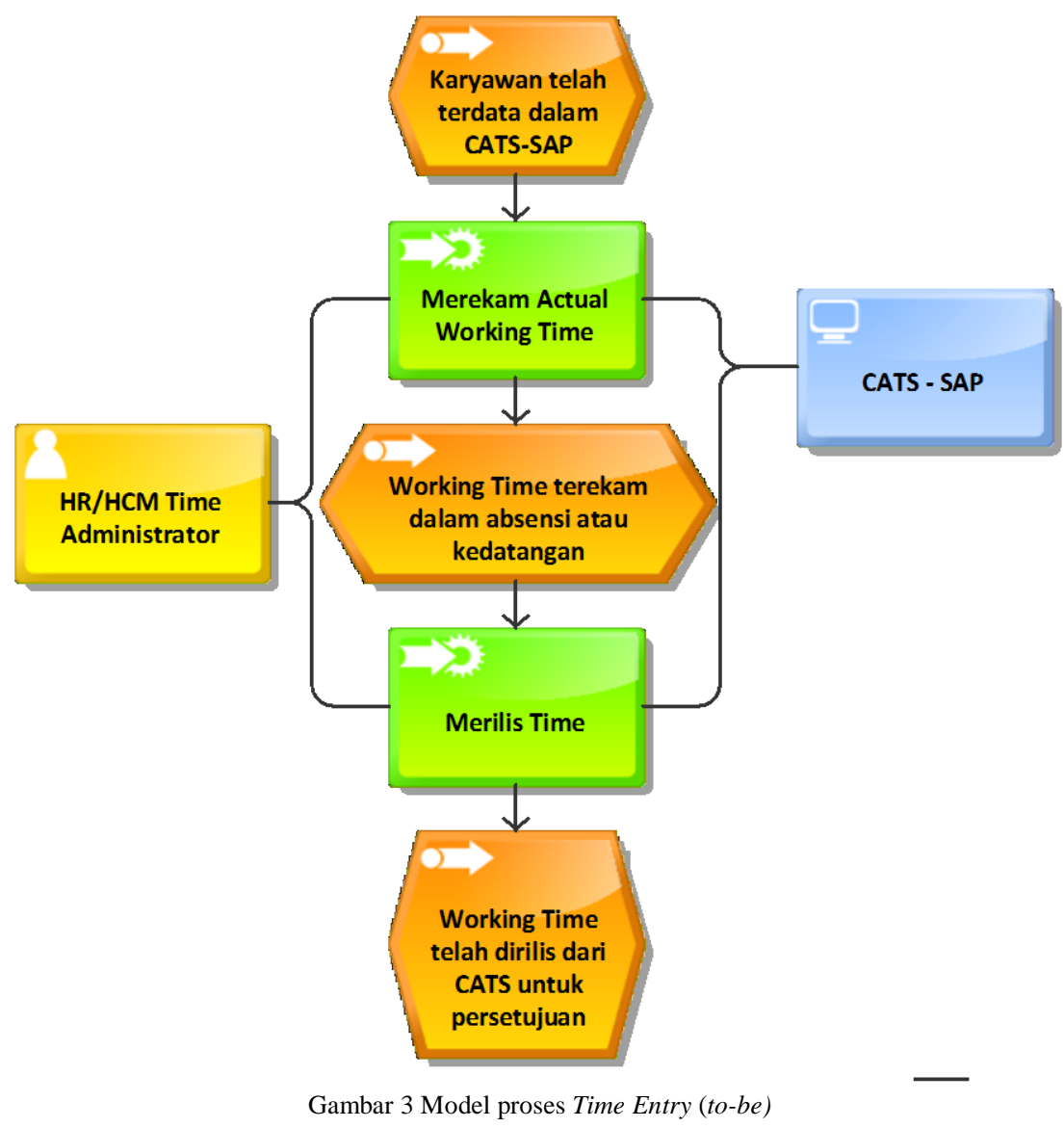




\subsection{Tahap Analisis Kesenjangan (Gap Analysis)}

Setelah semua proses dimodelkan, dilakukan analisis kesenjangan untuk mengetahui perubahan apa saja yang terjadi apabila proses bisnis to-be diimplementasikan serta dampak yang muncul akibat perubahan proses bisnis tersebut dan pengkategoriannya. Tabel 3 menampilkan contoh hasil analisis kesenjangan yang telah dilakukan berdasarkan quasi benefit analysis (Parker, et al., 1988) yang dikombinasikan dengan business value Category (Ranti, 2008).

Tabel 3 Hasil Analisis Kesenjangan

\begin{tabular}{|c|c|c|c|}
\hline \multicolumn{4}{|c|}{ Proses Bisnis "Time Management - Time Entry" } \\
\hline $\begin{array}{c}\text { Deskripsi } \\
\text { Perubahan }\end{array}$ & Dampak & $\begin{array}{c}\text { Business } \\
\text { Value } \\
\text { Category }\end{array}$ & $\begin{array}{l}\text { Kategori } \\
\text { Dampak }\end{array}$ \\
\hline $\begin{array}{l}\text { Aktivitas } \\
\text { Pembuatan } \\
\text { Struktur } \\
\text { Organisasi } \\
\text { dijalankan } \\
\text { oleh HCM } \\
\text { Administrator }\end{array}$ & $\begin{array}{l}\text { Diperlukan adanya } \\
\text { restrukturisasi } \\
\text { penambahan } \\
\text { fungsi/peran dalam } \\
\text { aktivitas } \\
\text { pembuatan struktur } \\
\text { organisasi atau } \\
\text { restrukturisasi } \\
\text { fungsi/peran dari } \\
\text { Staf SDM menjadi } \\
\text { HCM } \\
\text { Admnistrator. }\end{array}$ & $\begin{array}{l}\text { Meningkatk } \\
\text { an } \\
\text { produktivit } \\
\text { as fungsi } \\
\text { pekerjaan } \\
\text { bagi HCM } \\
\text { Time } \\
\text { Administrat } \\
\text { or. }\end{array}$ & $\begin{array}{l}\text { Value } \\
\text { Restructur } \\
\text { ing }\end{array}$ \\
\hline \multirow[t]{2}{*}{$\begin{array}{l}\text { Adanya } \\
\text { penyederhanaa } \\
\mathrm{n} \text { aktivitas } \\
\text { pada proses } \\
\text { pelatihan yang } \\
\text { diintegrasikan } \\
\text { dalam } \\
\text { Training \& } \\
\text { Event } \\
\text { Management }\end{array}$} & $\begin{array}{l}\text { Restrukturisasi } \\
\text { pengurangan } \\
\text { jumlah pekerjaan } \\
\text { aktivitas pada } \\
\text { kondisi To-Be } \\
\text { lebih sederhana } \\
\text { sehingga lebih } \\
\text { sedikit }\end{array}$ & $\begin{array}{l}\text { Meningkatk } \\
\text { an } \\
\text { produktivit } \\
\text { as dengan } \\
\text { adanya } \\
\text { restrukturis } \\
\text { asi } \\
\text { pekerjaan } \\
\text { dalam } \\
\text { pengadaan } \\
\text { pelatihan }\end{array}$ & $\begin{array}{l}\text { Value } \\
\text { Restructur } \\
\text { ing }\end{array}$ \\
\hline & $\begin{array}{l}\text { Meningkatkan } \\
\text { akurasi data } \\
\text { karena sebagian } \\
\text { besar pemrosesan } \\
\text { pengadaan } \\
\text { pelatihan } \\
\text { dilakukan dalam } \\
\text { satu sistem } \\
\text { terintegrasi SAP. }\end{array}$ & $\begin{array}{l}\text { Meminimal } \\
\text { isir resiko } \\
\text { kesalahan } \\
\text { data \& } \\
\text { meningkatk } \\
\text { an akurasi } \\
\text { data }\end{array}$ & $\begin{array}{l}\text { Value } \\
\text { Linking }\end{array}$ \\
\hline $\begin{array}{l}\text { Adanya Time } \\
\text { Management } \\
\text { dalam SAP } \\
\text { yang } \\
\text { terkoneksi } \\
\text { langsung } \\
\text { dengan CATS } \\
\text { yang merekap } \\
\text { data absensi } \\
\text { karyawan } \\
\text { secara } \\
\text { otomatis }\end{array}$ & $\begin{array}{l}\text { Adanya } \\
\text { percepatan } \\
\text { proses perekapan } \\
\text { data absensi }\end{array}$ & $\begin{array}{l}\text { Mempercep } \\
\text { at proses } \\
\text { data } \\
\text { preparation } \\
\text { dalam Time } \\
\text { Manageme } \\
\text { nt. }\end{array}$ & $\begin{array}{l}\text { Value } \\
\text { Accelerati } \\
\text { on }\end{array}$ \\
\hline
\end{tabular}

Sebagai tindak lanjut dari adanya kesenjangan ini, maka untuk mendukung kesuksesan implementasi ERP di PTPN XI diperlukan adanya manajemen perubahan organisasi. Bentuk manajemen perubahan organisasi pada implementasi ERP dapat berupa dilaksanakannya serangkaian aktivitas yang dapat menunjang keberhasilan dari implementasi ERP (Ali, 2016).

\section{KESIMPULAN}

Dari hasil analisis kesenjangan yang telah dilakukan, diketahui bahwa proses bisnis Human Capital Management eksisting di PTPN XI tidak dapat seluruhnya dipetakan pada proses bisnis best practice SAP. Hal ini dikarenakan proses bisnis eksisting memiliki birokrasi yang lebih kompleks sehingga beberapa proses tidak masuk dalam SAP. Selain itu, tidak semua proses bisnis manajemen SDM eksisting di PTPN XI tercakup dalam modul HCM melainkan dicakup pada modul lainnya di SAP.

Dari hasil gap analysis didapatkan tiga dampak utama dari implementasi modul HCM di PTPN XI, yakni:

- Value Restructuring: keseluruhan proses mengalami restrukturisasi fungsi/ peran dari kondisi eksisting ke kondisi to-be dan memiliki role yang lebih sedikit karena adanya penggunaan SAP pada setiap proses.

- Value Acceleration: dikarenakan sebagian besar proses/ aktivitas dilakukan dalam sistem SAP yang terintegrasi sehingga alur proses bisnis lebih sederhana yang menyebabkan terjadinya percepatan proses.

- Value Linking: proses bisnis yang lebih sederhana menyebabkan percepatan proses/ aktivitas, proses bisnis yang semakin cepat meningkatkan efektifitas dan efisiensi sehingga meningkatkan produktivitas manajemen sumber daya manusia di PTPN XI.

\section{DAFTAR PUSTAKA}

ALI, A. H. N., DARMANINGRAT, E. W. T. \& ANUNDRA, R. N., 2016. Identifikasi Aktivitas Manajemen Perubahan Organisasi pada Implementasi ERP di PT Perkebunan Nusantara XI Menggunakan Model ADKAR. Surabaya, The 2nd Conference on Innovation and Industrial Applications (CINIA).

ANASTHASIA, K. I., 2011. Teknologi Informasi dalam Organisasi, Jimbaran: SCRIBD.

CASCIO, W. F., 1990. Applied Psychology in Personnel Management. 4th penyunt. New Jersey: Prentice Hall College.

CRAIGER, J. P., 1996. Society for Industrial and Organizational Psychology. [Online] Available at: http://www.siop.org/tip/backissues/tipjan97/cr aiger.aspx

[Diakses 11 August 2015].

DAVENPORT, T. H., 1993. Process Innovation: Reengineering Work through Information 
Technology. Boston, Massachusetts: Harvard Business School Press.

INDRAJIT, R. E., 2001. Manajemen Sistem Informasi dan Teknologi Informasi. Jakarta: Elex Media Komputindo.

PARKER, M. M., Benson, R. J. \& Trainor, H. E., 1988. Information Economics: Linking Business Performance to Information Technology. 1st penyunt. New Jersey: Pearson College Div.

PTPN XI, 2013. About. [Online] Available at: http://www.ptpn-11.com/about [Diakses 11 August 2015].

RANTI, B., 2008. The Generic IS/IT Business Value Category: Cases in Indonesia. Jakarta, Konferensi dan Temu Nasional Teknologi Informasi dan Komunikasi untuk Indonesia.

SAP, 2016. SAP Best Practice. [Online] Available at: https://help.sap.com/viewer/p/SAP_Best_Prac tices [Diakses 29 February 2016].

SCHEER, A. W., Thomas, O. \& Adam, O., 2005. Process Modeling Using Event-Driven Process Chains. Dalam: W. v. d. A. A. H. M. t. H. Marlon Dumas, penyunt. Process-Aware Information Systems. New Jersey: John Wiley \& Sons, pp. 119-144.

UMBLE, E. J., Haft, R. R. \& Umble, M., 2003. Enterprise resource planning: Implementation procedures and critical success factors. European Journal of Operational Research, 146(2), pp. 241-257.

WIDAYANTO, 2017. Analisis Proses Bisnis Usaha Mikro Kecil Menengah (UMKM) Konveksi Ryan Collection di Kabupatan Kudus. Jurnal Administrasi Bisnis, 6(1), pp. 24-30. 
Halaman ini sengaja dikosongkan 